\title{
Negociando autoridades, construindo saberes: a historiografia digital e colaborativa no projeto Teoria da História na Wikipédia
}

\author{
Negotiating Authorities, Building Knowledge: \\ Digital and Collaborative Historiography \\ in the Project Theory of History on Wikipedia
}

Flávia Florentino Varella*

Rodrigo Bragio Bonaldo ${ }^{\star *}$

\section{Resumo}

Entre os projetos colaborativos de acesso gratuito de organização do big data destaca-se a Wikipédia, plataforma com ótimos resultados em buscadores que organiza e compila informações dispersas na rede, além de carregar, em seus verbetes, grande número de entradas dedicadas à história. A partir da experiência do projeto de extensão Teoria da História na Wikipédia, este artigo destaca o fenômeno da escrita da história nesta plataforma. Partimos do ponto de vista de que escrever a história em uma enciclopédia digital e colaborativa implica constantemente a negociação de autoridade. Por se tratar de uma história produzida com o público, transforma a orientação acadêmica em edição/ curadoria social, provocando estranhamentos com relação às práticas acadêmicas correntes. Advogamos, enfim,

\begin{abstract}
Among collaborative projects of free access to big data organization, Wikipedia stands out as a platform with great results in search engines which organizes and compiles information dispersed on the Web, in addition to uploading a large number of entries dedicated to history. Based on the experience of the extension project Theory of History on Wikipedia, this article highlights the phenomenon of writing history on this platform. We start from the point of view that writing history in a digital and collaborative encyclopedia constantly implies the negotiation of authority. Because it is a history produced with the public, it transforms academic orientation into social editing/curation, causing strangeness with respect to current academic practices. Finally, this article defends that it is possible to foster the
\end{abstract}

\footnotetext{
* Universidade Federal de Santa Catarina (UFSC), Florianópolis, SC, Brasil. flavia_varella@hotmail $<$ https://orcid.org/0000-0001-7123-8807>

** Universidade Federal de Santa Catarina (UFSC), Florianópolis, SC, Brasil. rodrigobonaldo@yahoo. com<https://orcid.org/0000-0002-3938-5169>
} 
pelo diálogo entre as regras da matriz disciplinar da escrita da história e os pilares do enciclopedismo digital, tais como expressos pela Wikipédia.

Palavras-chave: Teoria da História; Wikipédia; história pública; negociação de autoridades. dialogue between the rules of the disciplinary canon of writing history and the pillars of digital encyclopedism, as expressed by Wikipedia.

Keywords: Theory of History; Wikipedia; public history; negotiation of authority.

A Shared Authority sugere algo que é; que na natureza da história oral e da história pública nós não somos a única autoridade, os únicos intérpretes, os únicos autores-historiadores. Em vez disso, o processo de interpretação e construção de significados é, por definição, compartilhado

(Frisch, 2016, p. 62, grifos do autor).

O excesso de informação não é um fenômeno de todo novo. O enciclopedismo, em seu avatar moderno, nasceu como resposta a esse problema. Preocupava-se em compilar e tornar possíveis traduções, transcrições, fluxos e trocas de referências em meio à aceleração dos meios de produção e comunicação. Hoje, alguns séculos depois, chegamos a um "nível de transmissão de informação em tempo real" que produz um constante e "violento impacto aceleratório" (Rosa, 2019, p. 430, grifos do autor). Não é mais o som mecânico das rodas dentadas que imprime velocidade aos ritmos sociais, mas as notificações digitais de e-mails, WhatsApp e redes sociais. Experimentamos o tempo e vivemos em um mundo no qual as pressões aceleratórias se naturalizam na obrigação de estarmos atualizados, de maneira que, no limite, "o real, o efetivo, confunde-se com o mais atual, o mais recente” (Araujo; Pereira, 2018, p. 145). Simultaneamente, tornou-se comum dizer que vivemos na era do big data, do "dataísmo", de uma nova religião que "vê e compreende a economia em termos de processamento de dados" (Harari, 2016, p. 376). A transposição deste "limiar crítico" aceleratório (Rosa, 2019) é assim acompanhada pela produção de vasto volume de informações armazenadas nos chamados "bancos de dados". Artefatos culturais que desafiam toda atribuição de sentido, os $d a$ tabase tensionam de tal maneira concepções narrativas tradicionais que parecem habitar o epicentro de um problema fundamental para o "horizonte meta-histórico do século XXI” (Nicodemo; Cardoso, 2019, p. 21-22). Como sintoma e como resposta à força do tempo acelerado e à profusão informativa, surgem novas técnicas de organização e significação de amplas séries e coleções (Guldi; Armitage, 2018, p. 135-136). 
Dentro dessa nova economia da experiência do tempo está a Wikipédia, uma enciclopédia digital, colaborativa, de livre acesso e de atualização constante, que se caracteriza por compilar e administrar informações e saberes dispersos. A palavra Wiki significa, em idioma havaiano, rápido ou veloz, o que indica a possibilidade de esta linguagem apresentar informação para consumo imediato (Santana; Maynard, 2017, p. 26). Entre os verbetes da Wikipédia, encontramos também "[...] a maior obra de escrita da história on-line, a obra mais lida de história digital e o mais importante recurso histórico gratuito da World Wide Web" (Rosenzweig, 2006, p. 119). Demonstrando um excelente desempenho em motores de busca - os seus verbetes aparecendo, não raro, como primeiras entradas -, ela parece traduzir um potencial de difusão que não deveria ser negligenciado dentro dos debates da história pública. ${ }^{1} \mathrm{Em}$ face desse crescimento, uma questão se impõe: a Wikipédia é ou pode se tornar confiável, legítima, enquanto lugar de escrita e leitura da história?

Uma alternativa para começar a responder a essa questão é entender as práticas historiográficas na Wikipédia como localizadas em uma intersecção entre a história pública e a história digital. Neste artigo, trazemos como estudo de caso de uma historiografia pública e digital os trabalhos do projeto de extensão Teoria da História na Wikipédia. Desenvolvido na Universidade Federal de Santa Catarina (UFSC) por Flávia Florentino Varella e Rodrigo Bragio Bonaldo, a iniciativa tem como meta orientar estudantes de graduação e pós-graduação na produção de verbetes na área de Teoria da História e História da Historiografia. As características do projeto apontam para uma história produzia com o público, ou seja, "uma história colaborativa, na qual a ideia de 'autoridade compartilhada' é central” (Santhiago, 2016, p. 28), um tipo de história que demanda, como veremos, a constante negociação de autoridade entre os coordenadores, os bolsistas e os voluntários do projeto com a comunidade wikipedista. Entendemos que o desígnio de qualquer escrita da história é a elaboração de um "discurso legítimo sobre determinada experiência histórica”, e que os critérios de legitimidade discursiva são negociados em torno da relação entre "um autor, um relato e um receptor" (Nicolazzi, 2019, p. 207-208, grifos do autor). Consideramos, por outro lado, que os historiadores profissionais têm como responsabilidade a "busca honesta e metódica da verdade histórica" (Baets, 2013, p. 27). Seguindo esse duplo raciocínio, o objetivo deste artigo é debater as particularidades que essa relação assume dentro da Wikipédia, compreendendo, no âmbito do referido projeto de extensão, a colaboração como instauradora de tensões e negociações entre diferentes modalidades disciplinares: entre a história acadêmica e o enciclopedismo digital. 


\section{ENTRE DOIS MUNDOS}

Desafios relacionados às salvaguardas de acesso e à autoridade historiadora são por vezes recebidos como provocações que promoveriam a anulação do gatekeeping e a alienação daqueles que "têm habilidades técnicas" e "formação necessária para fazer sentido do passado como história” (Malerba, 2017, p. 143; Poster, 2003, p. 26). A desconfiança e, por vezes, hostilidade com a qual a Wikipédia é tratada pode ser lida na chave desse estranhamento. Sabe-se que há certos entraves dos docentes do ensino superior em relação à indicação da enciclopédia colaborativa como fonte de pesquisa (Vieira, 2008). ${ }^{2}$ Por não possuir nenhum tipo de curadoria de especialista, a dúvida sobre a qualidade da informação disponível para leitura na Wikipédia é reflexão recorrente entre aqueles que preferem outras fontes de informação, vistas como mais confiáveis. Em 2005, quatro anos após o lançamento da Wikipédia, a revista Nature comparou a qualidade da informação disponível na plataforma com o conteúdo de enciclopédias editadas por especialistas (Giles, 2005). Desde então, outros estudos foram realizados. Em consonância com o estudo da Nature, nenhum deles pôde atestar profundas diferenças entre os verbetes da Wikipédia e os da Enciclopédia Britânica, da Encarta, da American National Biography Online, da Enciclonet, da Mawsoah e da Enciclopédia Árabe. De forma geral, os verbetes da Wikipédia possuem extensão similar e número de imprecisões muito próximo aos das outras enciclopédias (Casebourne; Davies; Fernandes; Norman, 2012, p. 5-7; Giles, 2005; Ribeiro; Gottschalg-Duque, 2011, p. 176-181; Rosenzweig, 2006, p. 130).

Muitas das iniciativas associadas à Wikipédia na universidade buscam romper esse estereótipo da falta de confiabilidade e abrir um diálogo responsável entre o mundo acadêmico e o digital. Desde 2010, existem projetos que envolvem universidades e reformulação de verbetes. Essas iniciativas surgiram ao longo do desenvolvimento do projeto Wikipédia na Universidade. ${ }^{3}$ No Brasil, Juliana Bastos Marques iniciou em 2011 o primeiro projeto na área de história que editava verbetes da Wikipédia em seu "Tópico Especial em História Antiga - A história romana na Wikipédia”, ministrado na Universidade Federal do Estado do Rio de Janeiro (Marques, 2013). O projeto pioneiro de Marques inspirou professores a romper as barreiras entre o conhecimento produzido dentro da universidade e as amplas audiências do mundo virtual, assim como a enxergar a plataforma como uma maneira amigável de incentivar a leitura e a escrita de textos com domínio de referências confiáveis. São esses os casos de Flávia Florentino Varella, na disciplina obrigatória "História da Antiguidade Ocidental”, ministrada na Universidade Federal de Santa Ca- 
tarina, que trabalhou com edição de verbetes entre 2015 e 2017, e de Luís Filipe Silvério Lima, que em 2018 ministrou a disciplina "História Moderna II" na Universidade Federal de São Paulo. ${ }^{4}$

$\mathrm{Na}$ esteira dessas iniciativas, em 2018 foi lançado na UFSC o projeto de extensão Teoria da História na Wikipédia, coordenado por Varella e Bonaldo, fruto do amadurecimento das práticas didáticas previamente experimentadas pela cocoordenadora. Esse projeto, diferentemente dos anteriores e do que originalmente foi pensado pela Fundação Wikimedia, não esteve vinculado a nenhuma matéria curricular. Seu objetivo geral era ampliar e melhorar o conteúdo sobre Teoria da História e História da Historiografia na Wikipédia, de modo que audiências interessadas pudessem, desde o universo da língua portuguesa, ter acesso a conteúdo produzido por estudantes de graduação e pósgraduação sob a curadoria de Varella e Bonaldo. Além de contribuir para a disseminação de conteúdo de excelência por meio da plataforma, o projeto também visava a atender, num só tempo, o público em geral e os alunos de graduação e pós-graduação que consultam a enciclopédia. ${ }^{5}$

Durante os dois primeiros anos do projeto Teoria da História na Wikipédia, um grupo de 18 wikipedistas editou 97 verbetes na versão lusófona da enciclopédia, relacionados à Teoria da História e à História da Historiografia. Dentro desse universo, foram remodelados dez verbetes principais: Antiquário, Escola metódica, Filosofia da história, História do tempo presente, História dos conceitos, História global, História pública, Historicismo, Romance histórico e Scriptorium. Escritos em páginas de testes ao longo de um semestre letivo, cada verbete foi publicado num momento diferente, na medida em que o calendário de divulgação do projeto postulava que o produto final deveria ficar à disposição do usuário. ${ }^{6}$

O Gráfico 1 mostra que possui comprovação algorítmica a percepção de que representações populares do passado, como a Wikipédia, são capazes de atingir um vasto público e, por isso, são muitas vezes vistas como tendo impacto muito maior nas percepções das pessoas sobre a história do que os estudos difundidos nos moldes tradicionais universitários (Paletschek, 2011, p. 1-3). É difícil imaginar que as publicações das maiores autoridades no assunto alcancem, no intervalo de 20 dias, a marca de 836 visualizações atingida pelo verbete Historicismo, que obteve o melhor desempenho entre os verbetes principais do Projeto. ${ }^{7}$ Mas por que isso acontece? Nesse caso em específico, a questão nos leva à discussão a respeito dos critérios de ranqueamento dos buscadores digitais. 
Gráfico 1: Número de visualizações dos

verbetes entre 31/12/2019 e 20/1/2020

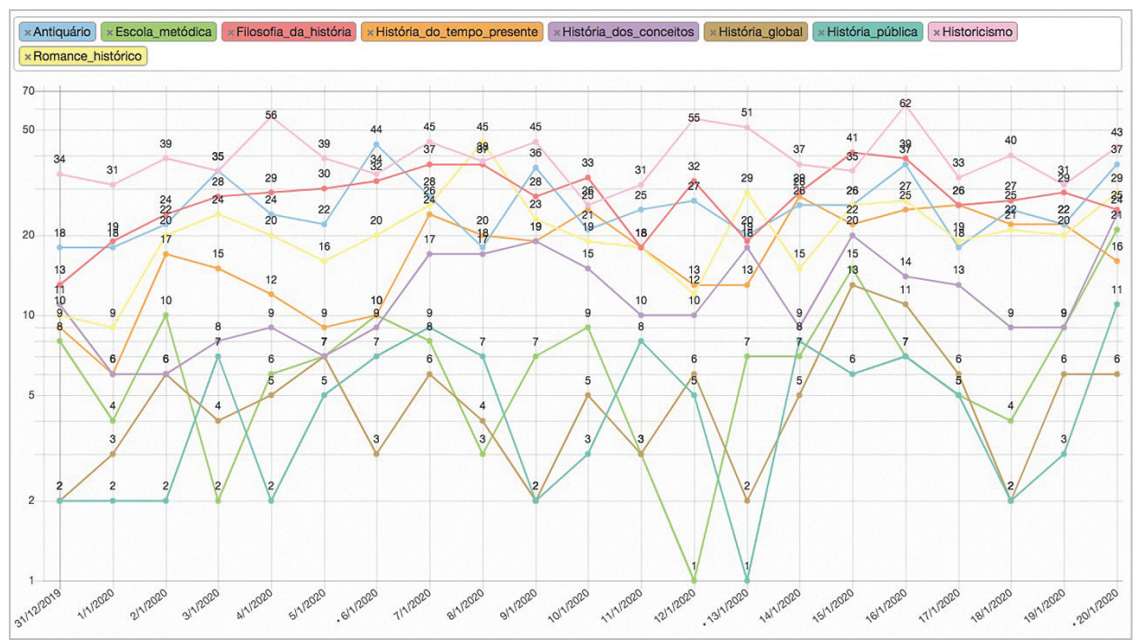

Fonte: Pageviews Analysis.

Incorporado entre as últimas atualizações, o mais antigo algoritmo do buscador Google hierarquiza a relevância das entradas através da quantidade e qualidade das ligações. Sob essa orientação, um website seria considerado melhor na medida em que fosse mais referenciado por páginas relevantes. Hoje, buscadores como o Google utilizam esse caminho entre cerca de outros 200 sinais ou fatores de ranqueamento. A lista não é pública. Algumas instruções gerais, organizadas em torno de 23 questões, foram anunciadas no blog oficial do Google no início da década (Singhal, 2011). Qualidade e profundidade de conteúdo, segurança, interface e velocidade em dispositivos portáteis seriam alguns exemplos de valências de classificação (Cutts, 2012). Ferramentas como a extensão Moz oferecem métricas que incluem os valores de ranqueamento com o objetivo de avaliar o desempenho de um domínio ou de uma página em um buscador. Nesse tipo de ferramenta, a autoridade de domínio (DA) é determinada pelo ranqueamento potencial relativo a outros domínios estabelecidos em um índex; a autoridade de página (PA) diz respeito às métricas de ligações. Já a autoridade dos sites é determinada (e representada em uma função logarítmica de 0-100) pelo destaque em meio à concorrência e pela relevância de uma tópica (por exemplo, a resposta a uma questão inserida em um buscador), elementos com os quais o conteúdo das páginas em avaliação deve competir para responder melhor (Moz). 
Nos verbetes desenvolvidos pelo projeto Teoria da História, a alta autoridade de domínio concedida pela Wikipédia (DA 95) torna a autoridade de página tanto mais elevada quanto mais for associada a ligações endógenas e externas. Sendo o grande número de hiperligações e redirecionamentos internos uma característica das plataformas Wiki, os sinais de ranqueamento associados aos domínios de página tendem a ser altos. O verbete Historicismo, mais acessado e hiperrelacionado, acaba tendo a mais alta autoridade de página entre os verbetes analisados. Isso significa que seu texto é capaz de responder questões postadas por usuários na plataforma Google. Esses fatores conspiram para um ótimo desempenho dos verbetes nos motores de busca mais populares da internet, figurando-os sempre entre as primeiras posições (Lopes, 2018, p. 149).

Todavia, nem todos os verbetes produzidos pelo projeto possuem projeção acentuada como o verbete Historicismo. Estratificando os menos vistos - História pública, Escola metódica e História global -, chegamos a dados menos animadores, segundo os quais as visualizações no período de 20 dias não ultrapassam a casa das centenas. Em média, esses verbetes possuem de cinco a sete visualizações (e não exatamente leitores) diárias. ${ }^{8}$ Também não é possível afirmar que o verbete seja lido por completo, já que sua estrutura enciclopédica permite ao usuário selecionar tópicos que melhor respondam aos seus questionamentos. Além disso, a quantidade de visualizações dos principais verbetes do projeto Teoria da História na Wikipédia está muito aquém dos mais acessados na plataforma, que possuem em torno de 300 mil visualizações mensais (Pageviews. Análise De...).

De qualquer forma, os dados apresentados descortinam aspectos importantes em relação às estratégias pelas quais historiadores profissionais podem comunicar pesquisas referenciadas às amplas audiências. A produção de forma colaborativa dos verbetes por professores e alunos, nas páginas de testes, e depois entre os participantes do projeto e a comunidade da Wikipédia, na votação para a escolha de artigo em destaque (EAD), abre espaço para se repensar a atuação e a prática do historiador, ao mesmo tempo que contribui para reativar "os vínculos entre universidade e sociedade" (Sousa; Gaio; Nicodemo, 2017, p. 72). Seria prudente sustentarmos que a cena atual de desafirmação das Humanidades e da insularidade dos historiadores "poderá ser respondida apenas pelo reforço da lógica da produção de conhecimento científico-especializado" (Araujo, 2017, p. 206)? Pelo contrário, há sinais de que a adoção do modelo atual de pesquisa, difundido na década de 1970 pela Coordenação de Aperfeiçoamento de Pessoal de Nível Superior no Brasil, contribuiu de forma direta 
para a situação de "baixa comunicação e legitimidade social do conhecimento academicamente produzido" (Araujo, 2017, p. 206). Nesse sentido, o projeto Teoria da História na Wikipédia pode ajudar a (re)pensar as possíveis funções de mediação da universidade no espaço público virtual.

\section{ESTRANHAMENTOS DISCIPLINARES}

Para o historiador, por mais que visitada com frequência, a Wikipédia não deixa de ser uma terra estrangeira. Regulada por normas de conduta próprias criadas pela comunidade de usuários, a enciclopédia livre apresenta um conjunto de práticas de produção e validação do conhecimento diferente das perpetradas no ambiente acadêmico. Dentre os dez verbetes principais produzidos pelo projeto Teoria da História, seis foram destacados e outros dois estão em processo de reformulação para votação. Produzir verbetes desse tipo, portanto, parece um objetivo central dessa iniciativa. $\mathrm{Na}$ Wikipédia existem três tipos de verbete: o de qualidade quatro ou inferior, o bom e o destacado. Os dois últimos tipos passam por um processo de votação entre usuários experientes da plataforma. Os verbetes de destaque precisam receber, no mínimo, sete votos e maioria qualificada de votos a favor $(\geq 75 \%)$ em um período de 30 dias, enquanto os bons precisam de ao menos cinco votos favoráveis e $100 \%$ dos votos a favor, durante 15 dias, ou sete votos favoráveis e maioria qualificada de votos a favor $(\geq 75 \%)$ em 30 dias, a partir da data de candidatura. Todos os verbetes eleitos de qualidade pela comunidade recebem uma estrela no canto superior direito da página principal. A estrela dourada indica um verbete destacado, e a estrela prateada, um bom. Essa marcação visual postula que o conteúdo foi rigidamente avaliado pelo grupo de usuários e considerado de grande contribuição para a Wikipédia (Wikipédia: Escolha do artigo...). Atualmente, existem na Wikipédia lusófona 1.163 artigos destacados, representando 0,11\% de todo o conteúdo da plataforma (Wikipédia: Artigos destacados).

Para poder participar da EAD, é necessário que o usuário registrado esteja logado, tenha realizado sua primeira edição há mais de 90 dias antes do início da votação e possua mais de 300 edições válidas no domínio principal (Wikipédia: Direito a voto). Portanto, a experiência na plataforma, e não o notório saber no assunto do verbete, é o critério essencial para se participar do processo de candidatura. Feitos esses esclarecimentos iniciais, podemos passar à análise da discussão promovida nas votações dos artigos destacados do projeto Teoria da História na Wikipédia. Ela nos ajuda a pensar a negociação da autoridade e da tradição da disciplina da história com o interesse e a agência 
historiográfica de públicos potencialmente não especializados. Por um lado, existem na Wikipédia interesses sobre o passado e procedimentos de pesquisa e escrita que não são exatamente científicos. Por outro, há fundamentos da matriz disciplinar histórica que corroboram certo incômodo de se ver agentes não especialistas escrevendo sobre história. Isso nos leva a reeditar uma importante questão do campo das Humanidades Digitais. Trata-se de nos perguntarmos de que modo poderíamos "melhor negociar os papéis de especialistas acadêmicos e usuários interessados e, em particular, como podemos estabelecer um controle de qualidade sem desencorajar o envolvimento dos usuários?" (Price, 2016, p. 137). Afinal, por meio do texto de apresentação da candidatura de cada verbete, a comunidade wikipedista estava ciente de que estava sob escrutínio a produção realizada por um grupo de profissionais treinados e em treinamento. No entanto, apenas com a chancela da comunidade seria possível ao Projeto alcançar seu objetivo de destacar os verbetes produzidos.

Um dos principais problemas levantados nesse processo de negociação de autoridade está no campo epistemológico. O segundo dos cinco pilares da enciclopédia aponta que "a Wikipédia se rege pela imparcialidade". ${ }^{9}$ Nesse sentido, o segundo pilar recomenda que "nenhum ponto de vista deve ser apresentado como o 'verdadeiro' e/ou o 'melhor', tampouco como o 'falso' e/ ou o 'pior”' (Wikipédia: Cinco pilares). É possível que a compreensão do “ponto de vista neutro" (PDVN) torne o segundo pilar o mais sujeito a desentendimentos entre o historiador disciplinado e os princípios que regem a Wikipédia, levando a uma dupla confusão. Em primeiro lugar, carrega expressões ("imparcialidade", "neutralidade") que as formações tradicionais rejeitam, em geral associadas a um certo "realismo ingênuo", a um "embuste liberal”, senão mesmo ao derrisório jargão do "positivismo". Trata-se da velha discussão da objetividade na história (Nicodemo; Cardoso, 2019, p. 35; Phillips, 2016, p. 533). Em segundo lugar, os critérios da Wikipédia não incentivam a objetividade estéril, menos ainda o revisionismo ou o negacionismo, cujos discursos alheios à referencialidade acabam expulsos e represados em outras plataformas de linguagem Wiki, como é o caso da Metapedia (Santana; Maynard, 2017). Como o texto do pilar deixa claro:

O Princípio da imparcialidade não afirma, ou implica, que deve-se dar "igual validade" a visões minoritárias como pseudociência, ou afirmações como que a "Terra é plana" ou que o "Holocausto nunca ocorreu". Se fosse o caso, o resultado seria validar ou até mesmo promover tais afirmações. A política afirma que não 
devemos tomar uma posição sobre estas questões, como escritores de uma enciclopédia, mas isso não nos impedirá de descrever visões majoritárias como tal; de explicar de forma justa os fortes argumentos contra a teoria pseudocientífica; de descrever a forte repugnância moral que muitas pessoas sentem frente a visões moralmente repugnantes; e assim por diante.

Em suma, o que vemos nesse pilar é um incentivo a uma espécie de pluralismo referencial, de acordo com o qual os verbetes deveriam ser "escritos em uma forma com a qual ambos (ou todos) os lados envolvidos possam concordar com ele" (Wikipédia: Princípio da...).

Essa questão mostrou-se de forma intensa na EAD do verbete História pública, em que a imagem da introdução do artigo foi questionada pelos votantes. No fundo da refotografia, que misturava fotos de manifestações de 2018 com as da Novembrada, apareciam três bandeiras da campanha presidencial de Fernando Haddad. Essa imagem vinha acompanhada da legenda "Projeto de história pública através da refotografia, mesclando protestos de $2018 \mathrm{com}$ os da Novembrada de 1979, em Florianópolis". ${ }^{10}$ Tanto a foto quanto a legenda geraram estranheza:

Não há "protestos de 2018" na refotografia utilizada como imagem principal, como se diz na legenda. Em vez disso, pelo que os elementos da figura permitem identificar, ela contém cenas de campanha eleitoral. Além dessa descrição descontextualizada acredito que outra imagem deveria ser selecionada para figurar como principal, desviando de tendências políticas e mantendo o alinhamento com o princípio da imparcialidade. --HVL disc. 16h32min de 12 de junho de 2019 (UTC - Universal Time Coordinated).

Na edição das 17h20min de 12 de junho de 2019, a imagem foi trocada pelo usuário Pedro Toniazzo Terres por uma nova refotografia livre de alusão política e que mostrava a fachada do Palácio Cruz e Souza. Em resposta a HVL na EAD, Terres afirmou: "Caro @HVL: Troquei a imagem para outra do mesmo projeto de refotografia, mas creio que sem permitir a interpretação que tivestes de determinada tendência política, veja o que acha; Pedro Toniazzo Terres (discussão) 17h25min de 12 de junho de 2019 (UTC)". Aparentemente sem intenção, através da escolha da imagem principal do verbete, Terres tendenciou-o à esquerda, não só por dar destaque a uma refotografia que continha elementos político-partidários, mas também por chamar as manifestações de protestos. Nesses gestos, mesclou os ideais da Novembrada com os das manifestações de 2018 e com o Partido dos Trabalhadores. Na visão do experiente 
wikipedista, isso era considerado o favorecimento de um ponto de vista e Terres teve que rever sua escolha imagética.

Já na votação para destaque do verbete Antiquário, o usuário Tetraktys argumentou a favor do respeito do princípio da imparcialidade com um problema heurístico em mente: a seção final do verbete, dedicada a descrever figurações literárias do antiquário, abandonava o tom generalista e apontava para casos particulares presentes nos escritos de Thomas Rowlandson, Walter Scott, Nietzsche e Montague Rhodes James. Com isso em mente, escreveu o votante: "esses quatro autores são especialmente relevantes ou foram os únicos a escrever sobre o tema, ou foi uma escolha a título de amostra? Tetraktys (discussão) 02h29min de 6 de julho de 2018 (UTC)" (Wikipédia: Escolha [...] Antiquário). Nesse caso, contudo, a discussão foi encerrada com a explicação de que "as figurações escolhidas não são as únicas, é claro, mas certamente constam entre as mais conhecidas, a julgar pela extensa pesquisa bibliográfica que realizamos. Mais uma vez, obrigado! --Alexandre Fiori (discussão) 13h38min de 6 de julho de 2018 (UTC)". Satisfeito ou não com a resposta, Tetraktys votou a favor do destaque do verbete salientado: "certamente um trabalho de alto nível".

Na prática do projeto de extensão, a reivindicação da exposição de diversos pontos de vista apareceu também com certa frequência como demanda por representatividade nacional. Afinal, o pilar indica que se deve apresentar "as diferentes visões sobre um assunto" "em proporção à proeminência de cada um" (Wikipédia: Princípio da imparcialidade). Na votação do destaque do verbete História dos Conceitos, os eleitores solicitaram a inclusão do estado da arte relativo a países que não haviam sido contemplados. O primeiro questionamento apareceu da seguinte forma: “em História_dos_conceitos\#Contextos_ nacionais, só aparecem quatro países: Brasil, Coreia do Sul, Espanha e Holanda. À primeira vista, isto parece uma escolha completamente aleatória e arbitrária. Existe alguma razão para serem mencionados apenas estes quatro? JMagalhães (discussão) 18h37min de 12 de abril de 2019 (UTC)" (Wikipédia: [...] História dos conceitos). Dois dias depois, o usuário Estranho no Ninho questionou sobre a ausência, nessa mesma seção, de Portugal, da América Latina e da Alemanha, tendo em vista que um dos fundadores da História dos Conceitos era alemão. No dia 17 de abril, Gabriel bier apontou também a ausência da Itália. Após algumas respostas e reformulações efetuadas pelo usuário Alexandre Fiori, a discussão foi encerrada, mas parece ter produzido ruídos dentro da comunidade, tendo em vista que ela reapareceu na EAD do verbete História pública. Dessa vez, o debate foi bem mais acirrado: 
Magalhães (discussão) $11 \mathrm{~h} 07 \mathrm{~min}$ de 27 de maio de 2019 (UTC) Voto aqui por violação de-WP:NPOV $(\underline{\text { WP:PESO}})$ e pelo texto estar manifestamente incomple= to. Hourve una votação en que ignorei, mas isto já se começa a tornar um hábito: qual é a razão para só terem sido escolhidos meia dúzia de países? Nos outros não há história públiea? Das duas uma. ou 1) este artigo se limita a definir 0 eonceito de uma perspetiva neutra global, sem entrar em detalhes por país; out 2) se vai abordar eada pás individualmente, então que o faça para todos os páses onde o tópico exista, e não apenas para meia dúzia deles. O que nãose podé entrar em detalhes excessivos para uns, enquanto outros são totalmente ignoratos.

Não apenas JMagalhães havia ficado insatisfeito com a resolução da questão similar no verbete História dos Conceitos, Gabriel bier também expressou seu descontentamento com o modelo editorial com base em "contextos nacionais" argumentando que:

Venha a concordar com o IMagalhães. Aliás, recentemente houve um caso se=

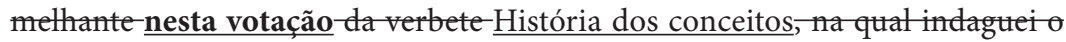
autor enn questão, não obtendo una resposta sobre o caso. Por enquanto, evitarei eair no mesmo erro em votar precipitadamente e esperarei a proponente se maniffestar. Gabriel bier fala aew 15 h09 min de 28 de maio de 2019 (UTC). ${ }^{11}$

No caso do verbete História pública, foi criado um verbete chamado História pública por países, sugestão do usuário JMagalhães, e o problema da imparcialidade foi interpretado como solucionado pela comunidade.

Contudo, a discussão não foi tão facilmente contornada na votação de destaque do verbete História do tempo presente. Em 5 de agosto de 2018, um eleitor escreveu:

Infelizmente percebi o que na minha visão é uma lacuna pertinente no verbete: não há qualquer perspectiva ou relato sobre o que é e como é a História do tempo presente em Portugal [...]. Então, se existe uma História do tempo presente na perspectiva e história/historiografia/acadêmica do Brasil, seria recomendável (até para os editores de Portugal desta comunidade, afinal eles existem), uma História do tempo presente na perspectiva de Portugal [...].Sdç. --Zoldyick (discussão) 18 h13min de 5 de agosto de 2018 (UTC). ${ }^{12}$

Dada a inexpressividade do campo da História do tempo presente em Portugal, os participantes do projeto decidiram que não restava alternativa, 
ante a não referencialidade, senão sustentar que não era possível agregar a demanda do usuário Zoldyick. ${ }^{13}$ Contudo, o que o wikipedista experiente estava argumentando era que a estruturação montada do verbete privilegiava determinados países enquanto apagava e invisibilizava outros. O projeto Teoria da História na Wikipédia estava ferindo o princípio da imparcialidade ao não dar o devido peso às visões marginais sobre o assunto. Por mais que a bibliografia consultada pelos integrantes do Projeto indicasse que existiam alguns lugares com profusão maior de debate sobre o tema, isso não poderia levar ao alijamento dos locais em que o debate ainda era pequeno, mas existente. De qualquer forma, não se sabe se por causa dessa recusa em ser atendido ou pelo desejo de melhorar o conteúdo da Wikipédia, Zoldyick retomou a votação alegando que o verbete descumpria o Livro de Estilo, explicando que "algumas notas apresentam a paginação, o que é um requisito [para o destaque], enquanto outras negligenciam isso. É algo importante que precisa ser revisto para uma devida verificação do verbete. Sdç. - Zoldyick (discussão) 01h04min de 16 de agosto de 2018 (UTC)”. Apesar de o usuário Igor Lemos Moreira afirmar que iria corrigir esse erro, acabou não o fazendo, o que levou Zoldyick a votar no verbete como bom.

O princípio da verificabilidade da informação e da imparcialidade são dois dos três princípios inegociáveis dentro da Wikipédia (Wikipédia: Verificabilidade). Estando cientes de que os usuários da plataforma criam a maioria das regras pelas quais são geridos, conseguimos vislumbrar a importância que esses princípios tem para a comunidade enquanto diretrizes fundantes da plataforma. Foi na junção desses dois problemas que aconteceu um momento crítico dentro do Projeto, com o processo simultâneo de eliminação de cinco verbetes: Verena Alberti, Carlos Fico, Rodrigo Patto Sá Motta, Marieta de Moraes Ferreira e Pieter Lagrou. ${ }^{14}$ Esses verbetes, classificados pelo Projeto como secundários, foram escritos para complementar a leitura do verbete principal História do tempo presente e visavam ao azulamento de ligações internas, critério importante para o destaque (Wikipédia: O que é...).

A discussão sobre a eliminação foi iniciada no dia 25 de julho de 2018, no Café dos Administrados, pelo usuário Felipe da Fonseca, que participava como embaixador no Projeto. No fórum destinado ao debate interno da comunidade, Fonseca pedia aos wikipedistas que avaliassem a notoriedade dos verbetes e, caso concordassem com sua avaliação, que abrissem os pedidos de eliminação. É princípio base para existência de um artigo na Wikipédia estar de acordo com os critérios de notoriedade, que pregam a "cobertura significativa de fontes reputadas e independentes”, ou com critérios temáticos estabelecidos 
pela comunidade. Exceto por Fico e Lagrou, os demais verbetes foram tidos de antemão pelos wikipedistas como não notórios. Como ninguém transformou a palavra em ação, Fonseca abriu, ele mesmo, o pedido de eliminação para todos os cinco verbetes no dia seguinte (Wikipédia: Café dos eliminadores).

A argumentação principal nas páginas de eliminação girava em torno das fontes, que não provavam a notoriedade dos biografados. Todas as discussões de eliminação apontavam que as referências citadas eram parcas e, algumas vezes, enviesadas, pois se tratava de entrevistas com os biografados. Esse tipo de conteúdo é considerado pelas normas da comunidade como não credíveis e independentes, pois são "fontes publicadas pelo próprio" ou de "fiabilidade duvidosa” (Wikipédia: Verificabilidade). Ao longo da discussão, percebe-se a dificuldade dos participantes do Projeto em argumentar nos termos de validade da Wikipédia, retomando aspectos importantes para a academia, mas insignificantes para a enciclopédia. Foi constante a argumentação sobre a ocupação de cargos de prestígio, que reiteradas vezes foi rebatida por experientes wikipedistas com o mantra de que cargos político-administrativos não transmitem notoriedade. Para resumir a contenda, dos cinco artigos propostos para eliminação, apenas o de Verena Alberti não sobreviveu ao escrutínio, pois a biografada foi considerada "profissional no exercício de sua profissão". Os demais sofreram reformulações que permitiram provar a notoriedade dos biografados por meio de fontes consideradas independentes e confiáveis. Por uma série de fatores, as biografias de pessoas vivas formam um dos temas mais controversos da Wikipédia (D’Andréa, 2011). Nesse caso, porém, talvez por falta de experiência com as regras da plataforma, os membros do projeto Teoria da História na Wikipédia tiveram que negociar a sua autoridade com a comunidade e atender aos pedidos de reformulação. Em um caso limite, porém, a eliminação foi sumária, pois não foi possível comprovar que o verbete seguia as regras da Wikipédia e poderia ser mantido.

Não é de hoje que o colaboracionismo é destacado como um dos aspectos centrais na produção dos verbetes pela comunidade de usuários da Wikipédia (Phillips, 2016, p. 538). Essa dimensão colaborativa da enciclopédia aberta desafia a forma como tradicionalmente os pesquisadores, inclusive aqueles oriundos da Teoria da História e da História da Historiografia, vêm desenvolvendo seus trabalhos. ${ }^{15} \mathrm{~A}$ lógica de edição dos verbetes na Wikipédia também traz, portanto, desafios de ordem pragmática ao historiador, sobretudo ao desestabilizar a noção moderna de autoria por meio da "proliferação dos sujeitos e lugares de produção do conhecimento histórico [...] para além dos círculos especializados" (Abreu; Bianchi; Pereira, 2018, p. 283-284). Essas observações 
se mostraram coerentes, sobretudo através das sugestões de mudanças e incorporações nas EADs feitas pela comunidade. A produção colaborativa desloca práticas tradicionais de escrita e tensiona noções modernas de autoria. Diante desse quadro potencialmente composto por vozes diversas - unidas na autoria coletiva que negocia autoridades para além de uma função delegada do poder disciplinar -, podemos nos apropriar do princípio da "neutralidade do ponto de vista" não como um ingênuo atavismo realista, sequer como um ideal axiológico a serviço de um pluralismo sem compromisso referencial, mas como uma condição de possibilidade, talvez, para a emergência de histórias alternativas, de narrativas cuja medida de "indisciplina" seja também indício de aproximação e intercâmbio com demandas sociais pelo passado. Demandas, ainda assim, orientadas pelos princípios éticos que sustentam o uso responsável da história: o rigor em buscar a verdade e a sinceridade para dizê-la (Baets, 2013, p. 23). São princípios, como vimos, em nada contraditórios tanto com os pilares da Wikipédia quanto com as práticas de sua comunidade digital.

De todo modo, o embate analisado mostra como os dispositivos Wiki se caracterizam por desverticalizar as hierarquias tradicionais na profissão do historiador (Maynard, 2016; Rosenzweig, 2006, p. 136-140). Para tanto, os agentes estabelecem algo como uma "negociação estigmérgica" (Bruns, 2008, p. 110), mantendo-se em comunicação mútua, horizontal e independente. ${ }^{16}$ É dessa maneira que entendemos a Wikipédia como um produto editorial que busca conciliar a tradição das antigas enciclopédias iluministas com os novos horizontes de publicação abertos pela tecnologia computacional, horizontes que facilitam a construção colaborativa do conhecimento em tempo real. Os verbetes disponíveis para consulta e edição na plataforma são trabalhos em contínua elaboração, constantemente reescritos, e não buscam a perfeição para depois almejarem a publicação (D’Andréa, 2011, p. 43-54). A possibilidade aberta pela contribuição imediata de leitores é um fenômeno muito particular à Wikipédia. Com ela mudam-se relações antes estabelecidas entre autor, leitor e texto no meio impresso (D’Andréa, 2011, p. 55-56). Sua lógica é a da organização de dados volúveis e dispersos na internet, promovendo um reordenamento, através de hiperligações entre informações particulares, do "microcosmo das estruturas da rede mais ampla” (Bruns, 2008, p. 102). Ainda, para seguir o vocabulário de Pereira e Araújo (2018, p. 55), a credibilidade dos verbetes da Wikipédia depende, com frequência, da capacidade compilatória de reproduzir uma realidade em constante atualização.

A cultura digital na qual a Wikipédia está imersa contorna não só muitas das práticas tradicionais "de leitores e árbitros especialistas situados em edito- 
ras e periódicos", ao permitir que a informação esteja à disposição do público em geral para consumo, mas também muda as práticas de manipulação dessa informação (Lopes, 2018; Poster, 2003, p. 25-26). O controle coletivo da informação "combina facilidade de uso, transparência e arquivamento automático de toda edição realizada" (Vandendorpe, 2015, p. 3). A plataforma concilia dessa maneira uma comunidade engajada na vigília dos verbetes com registros instantâneos de edições, oferecendo segurança quanto a vandalismos e adições não verificáveis, as quais podem ser revertidas com celeridade. Sendo "qualquer informação postada em um artigo [...] escrutinada por uma variedade de contribuidores", a Wikipédia procura se apresentar como uma fonte dotada de mecanismos que buscam garantir a confiabilidade da informação (Vandendorpe, 2015, p. 5). A novidade trazida pela Wikipédia é a proposta de oferecer essas salvaguardas a partir do diálogo de "múltiplas vozes competindo na enciclopédia" (O’Sullivan, 2009, p. 125): uma competição, ainda assim, regulada por normas de conduta. Assim, o conhecimento produzido na Wikipédia faz parte de um processo social de interação e edição entre os wikipedistas, segundo o qual se espera que a comunidade de usuários, a partir da publicação de uma entrada, inicie o que pode ser um longo processo de avaliação que perpassa a crítica, a edição e o desenvolvimento do verbete, mas que pode ter um desfecho de eliminação daquilo que foi escrito.

\section{CONSIDERAÇÕES FINAIS}

A Wikipédia tem a capacidade de organizar e administrar saberes e informações espalhadas pela web. Sua linguagem permite o rápido acesso ao conteúdo, o que aproxima a enciclopédia do modo acelerado como a informação é consumida na rede. Dentro de seus verbetes, a plataforma acolhe o maior projeto de escrita colaborativa da história disponível on-line. Neles, ficam inscritos toda a edição, todo o debate e toda a mudança, constituindo igualmente um arquivo a respeito de seus processos e conflitos de escrita (Pereira, 2015). Disciplinada por um discurso enciclopédico e sustentada por mecanismos de controle e reprodução ligados ao fenômeno da internet 2.0, a plataforma ocupa igualmente um lugar de divulgação e de tensão para com as práticas historiográficas profissionais. Restou-nos, ao explicitar as experiências do projeto de extensão Teoria da História na Wikipédia, problematizar os possíveis impactos, negações e trocas entre historiografia acadêmica e verbetes enciclopédicos digitais quando ambos visam, de formas contingentes e através de regras autônomas, negociar representações legítimas do passado. 
O objetivo do projeto de extensão supracitado é o de fazer bolsistas e voluntários produzirem, sob a orientação de professores universitários, verbetes qualificados na área de Teoria da História e História da Historiografia. Esse desígnio por si só já supõe, no entanto, uma negociação: qualificados do ponto de vista acadêmico, os verbetes, quando lançados à candidatura do destaque, necessitam também adequar-se aos critérios de legitimidade da comunidade lusófona da Wikipédia. Assim, a orientação torna-se, na prática, uma espécie de curadoria, mera moderadora da escrita da história em ambientes digitais nos quais imperam práticas de "edição social" (Araújo, 2017, p. 209; Terres; Piantá, 2020 , p. 282). Esse contato com usuários potencialmente não especializados levou os participantes do projeto a uma experiência de alteridade. Como visto ao longo deste artigo, o diálogo com a comunidade não se restringe à sugestão de incorporação ou exclusão de informações ou à remodelação de seções, mas afeta diretamente a forma como o conhecimento é construído.

A Wikipédia é uma comunidade de práticas que tem o conhecimento participativo como fundamento (O'Sullivan, 2009, p. 3). Por causa dessas características, a plataforma tem uma dinâmica de produção de conteúdo que inviabiliza o padrão tradicional impresso, fundado na autoria e na preparação e revisão anterior à publicação. Isso não significa, por outro lado, que os membros da comunidade não sejam tão interessados ou zelosos a respeito da qualidade dos verbetes. Significa, em primeiro lugar, que os verbetes estão em constante atualização. Se formos ler as demandas que o Projeto recebeu dos membros da comunidade como parte de uma negociação mais ampla pela legitimidade dos verbetes, entenderemos que parcela considerável das reivindicações dizia respeito às dimensões heurísticas e epistemológicas.

Os resultados apresentados ainda fazem impor uma série de questões. Afinal, reconhecer, debater, negociar e dar significado a estes estranhamentos disciplinares não seria também tarefa para aqueles que se dedicam a estudar a disciplina, a teoria e o estado da escrita da história no tempo presente? Seria possível, enfim, negociar autoridades em meio digital sem realizar concessões substantivas que descaracterizem as habilidades e as competências fundamentais da historiografia profissional? De resto, se julgarmos o caso positivamente, caberia ao historiador seguir a reflexão a respeito do que mudou com a chegada das novas tecnologias digitais. Nada mais do que detalhes do cotidiano, de como as fontes são acessadas, de como a bibliografia é consultada, e de que forma o material dos cursos pode ser organizado? (Silveira, 2018; Moura; Maynard, 2016). 


\section{REFERÊNCIAS}

ABREU, Marcelo; BIANCHI, Guilherme; PEREIRA, Mateus. Popularizações do passado e historicidades democráticas: escrita colaborativa, performance e práticas do espaço. Tempo e Argumento, Florianópolis, v. 10, n. 24, p. 279-315, 2018.

ALEXA. The top 500 sites on the web. Disponível em: https://www.alexa.com/topsites. Acesso em: 01 mai. 2019.

ARAUJO, Valdei. O Direito à História: $\mathrm{O}(\mathrm{A})$ Historiador(a) como Curador(a) de uma experiência histórica socialmente distribuída. In: GUIMARÃES, Géssica; BRUNO, Leonardo; PEREZ, Rodrigo. Conversas sobre o Brasil: ensaios de crítica histórica. Rio de Janeiro: Autografia, 2017. p. 191-216.

ARAUJO, Valdei; PEREIRA, Mateus. Atualismo 1.0: como a ideia de atualização mudou o século XXI. Vitória: Editora Milfontes/ Mariana: Editora SBTHH, 2018.

BAETS, Antoon de. Uma teoria do abuso da História. Revista Brasileira de História, São Paulo, v. 33, n. 65, p. 17-60, 2013.

BRUNS, Axel. Blogs, wikipedia, second life, and beyond: from production to produsage. New York: Peter Lang, 2008.

CASEBOURNE, Imogen; DAVIES, Chris; FERNANDES, Michelle; NORMAN, Naomi. Assessing the accuracy and quality of Wikipedia entries compared to popular online encyclopedias: a comparative preliminary study across disciplines in English, Spanish and Arabic. Brighton, UK: Epic, University of Oxford, 2012. 77 p.

CUTTS, Matt. Another step to reward high-quality sites. Google Webmaster Central Blog. 24 abr. 2012. Disponível em https://webmasters.googleblog.com/2012/04/ another-step-to-reward-high-quality.html. Acesso em: 17 jun. 2019.

D'ANDRÉA, Carlos Frederico de Brito. Processos editoriais auto-organizados na Wikipédia em português: a edição colaborativa de "Biografia de pessoas vivas". Tese (Doutorado em Linguística Aplicada) - Programa de Pós-Graduação em Estudos Linguísticos da Faculdade de Letras, Universidade Federal de Minas Gerais, Belo Horizonte, 2011. 333 p.

FRISCH, Michael. A História Pública não é uma via de mão única: ou, De $A$ Shared Authority à cozinha digital, e vice-versa. In: MAUAD, Ana Maria; ALMEIDA, Juniele Rabêlo de; SANTHIAGO, Rocardo (Orgs.). História Pública no Brasil: Sentidos e Itinerários. São Paulo: Letra e Voz, 2016. p. 57-70.

GILES, Jim. Internet encyclopaedias go head to head. Nature, London, v. 438, p. 900-901, 2005.

GLOTT, Ruediger; SCHMIDT, Phillipp; GHOSH, Rishab. Wikipedia Survey: Overview of Results. 2010. Disponível em: https://web.archive.org/web/20110728182835/http:// www.wikipediastudy.org/docs/Wikipedia_Overview_15March2010-FINAL.pdf. Acesso em: 24 jan. 2020. 
GULDI, Jo; ARMITAGE, David. Manifesto pela História. Belo Horizonte: Autêntica, 2018.

HARARI, Yuval Noah. Homo Deus: uma breve história do amanhã. Tradução de Paulo Geiger. São Paulo: Cia das Letras, 2016.

JOHNSON, Telma Sueli Pinto. Nos bastidores da wikipédia lusófona: percalços e conquistas de um projeto de escrita coletiva online. Tese (Doutorado em Comunicação) - Programa de Pós-Graduação em Comunicação Social, Universidade Federal de Minas Gerais, Belo Horizonte, 2009. 273 p.

LOPES, André Pereira Leme. Virada digital? Pesquisa histórica no ciberespaço. Tempo e Argumento, Florianópolis, v. 10, n. 24, p. 136-169, 2018.

MACHUY, Camilla Cavalcante de Souza. Wikipédia midiática: cotidianidades, compilação de saberes e lutas de poder nos bastidores da Enciclopédia Livre. Dissertação (Mestrado em Mídia e Cotidiano) - Instituto de Arte e Comunicação Social, Universidade Federal Fluminense, Rio de Janeiro, 2016. 88 p.

MALERBA, Jurandir. Os historiadores e seus públicos: desafios ao conhecimento histórico na era digital. Revista Brasileira de História, São Paulo, v. 37, n. 74, p. 135-154, 2017.

MARQUES, Juliana. Bastos. Trabalhando com a história romana na Wikipédia: uma experiência em conhecimento colaborativo na universidade. Revista História Hoje, São Paulo, v. 2, n. 3, p. 329-346, 2013.

MAYNARD, Dilton Cândido Santos. Passado eletrônico: notas sobre história digital. Acervo, Rio de Janeiro, v. 29, n. 2, p. 103-116, 2016.

MOURA, Luyse Moraes; MAYNARD, Dilton Cândido Santos. Apontamentos sobre História Digital: a internet nos livros didáticos do PNLD 2015. Labirinto, v. 24, n. 2 , p. 175-194, 2016.

MOZ. Meet Link Explorer. Disponível em https://moz.com/link-explorer. Acesso em: 29 jan. 2019.

NICODEMO, Thiago Lima; CARDOSO, Oldimar. Metahistory for (Ro)bots: historical knowledge in the artificial intelligence era. História da Historiografia, v. 12, n. 29, p. 17-52, 2019.

NICOLAZZI, Fernando. Os historiadores e seus públicos: regimes historiográficos, recepção da história e história pública. Revista História Hoje, São Paulo, v. 8, n. 15, p. 203-222, 2019.

O'SULLIVAN, Dan. Wikipedia: a new community of practice? Farnham: Ashgate, 2009. PALETSCHEK, Sylvia. Introduction: Why Analyse Popular Historiographies? In: PALETSCHEK, Sylvia (Ed.). Popular Historiographies in the 19th and 20th Centuries: Cultural Meanings, Social Practices. New York, Oxford: Berghahn Books, 2011. p. 1-18.

PAGEVIEWS Analysis. Disponível em: https://bit.ly/3dZFBqi. Acesso em: 26 out. 2020. 
PAGEVIEWS. Análise de páginas mais vistas. Disponível em: https://tools.wmflabs.org/ topviews/?project=pt.wikipedia.org\&platform $=$ all-access\&date $=2019-12 \&$ excludes $=$. Acesso em: 21 jan. 2020.

PAGEVIEWS. Visualizações da página. Disponível em < https://tools.wmflabs.org/ pageviews/?project=pt.wikipedia.org\&platform $=$ all-access\&agent=user\&start=201912-31\&end=2020-01-20\&pages=Historicismo $>$. Acesso em: 20 jan. 2020.

PANDE, Mani. Wikipedia editors do it for fun: First results of our 2011 editor survey. Wikimedia blog. 10 Jun. 2011. Disponível em: https://blog.wikimedia.org/2011/06/10/ wikipedia-editors-do-it-for-fun-first-results-of-our-2011-editor-survey/. Acesso em: 24 jan. 2020.

PEREIRA, Mateus Henrique de Faria. Nova direita? Guerras de memória em tempos de Comissão da Verdade (2012-2014). Varia Historia, Belo Horizonte, v. 31, n. 57, p. 863-902, 2015.

PHILLIPS, Murray G. Wikipedia and history: a worthwhile partnership in the digital era?. Rethinking History, London, v. 20, n. 4, p. 523-543, 2016.

POSTER, Mark. History in the digital domain. Historein, Atenas, v. 4, n. 4, p. 17-32, 2003.

PRICE, Kenneth M. Social Scholarly Editing. In: SCHREIBMAN, Susan; SIEMENS, Ray; UNSWORTH, John (Eds.). A new companion to digital humanities. Chichester, UK: John Wiley \& Sons, Ltd., 2016. p. 137-149.

RIBEIRO, Aline Luli Romero; GOTTSCHALG-DUQUE, Cláudio. Wikipédia e enciclopédia britânica: Informação confiável?. Revista Brasileira de Biblioteconomia e Documentação, São Paulo, v. 7, n. 2, p. 172-185, 2011.

ROSA, Hartmut. Aceleração: a transformação das estruturas temporais na Modernidade. Tradução de Rafael H. Silveira. Revisão técnica e tradução do prefácio à edição brasileira de João Lucas Tziminadis. São Paulo: Editora Unesp, 2019.

ROSENZWEIG, Roy. Can history be open source? Wikipedia and the future of the past. The Journal of American History, Bloomington, v. 93, n. 1, p. 117-146, 2006.

SANTANA, Diego Leonardo; MAYNARD, Dilton. O portal Metapedia: revisionismo histórico e negacionismo no tempo presente. Transversos: Revista de História, n. 11, p. 23-41, 2017.

SANTHIAGO, Ricardo. Duas palavras, muitos significados. In: MAUAD, Ana Maria; ALMEIDA, Juniele Rabêlo de; SANTHIAGO, Rocardo (Org). História Pública no Brasil: Sentidos e Itinerários. São Paulo: Letra e Voz, 2016. p. 23-36.

SILVEIRA, Pedro Telles da. História, técnica e novas mídias: reflexões sobre a história na era digital. Tese (Doutorado em História Social) - Programa de Pós-Graduação em História do Instituto de Filosofia e Ciências Humanas da Universidade Federal do Rio Grande do Sul, Porto Alegre, 2018. 375 p.

SINGHAL, Amit. More guidance on building high-quality sites. Google Webmaster Central Blog. 2011. Disponível em: https://webmasters.googleblog.com/2011/05/more-guidance-on-building-high-quality.html. Acesso em: 30 out. 2020. 
SOUSA, Francisco Gouveia de; GAIO, Géssica Guimarães; NICODEMO, Thiago Lima. Uma lágrima sobre a cicatriz: o desmonte da Universidade Pública como desafio à reflexão histórica. Revista Maracanan, Rio de Janeiro, n. 17, p. 71-87, 2017.

TERRES, Pedro Toniazzo; PIANTÁ Lucas Tubino. Wikipédia: públicos globais, histórias digitais. Esboços, Florianópolis, v. 27, n. 45, p. 264-285, 2020.

VANDENDORPE, Christian. Wikipedia and the Ecosystem of Knowledge. Scholarly and Research Communication, CISP Press, v. 6, n. 3, p. 1-10, 2015.

VARELLA, Flávia. Limites, desafios e perspectivas: a primeira década da revista História da Historiografia (2008-2018). História da Historiografia, Ouro Preto, v. 11, n. 28, p. 219-265, 2018.

VIEIRA, Marli Fátima Vick. A Wikipédia é confiável? Credibilidade, utilização de uma enciclopédia online no ambiente escolar. Dissertação (Mestrado em Educação) Programa de Mestrado Acadêmico em Educação, Universidade do Vale do Itajaí, Itajaí, 2008. $157 \mathrm{p}$.

WIKIPÉDIA: Artigos destacados. Disponível em https://pt.wikipedia.org/wiki/ Wikip\%C3\%A9dia:Artigos_destacados. Acesso em: 21 jan. 2020.

WIKIPÉDIA: Café dos eliminadores/Arquivo/2018/07-12. Disponível em: https:// pt.wikipedia.org/wiki/Wikip\%C3\%A9dia:Caf\%C3\%A9_dos_eliminadores/Arquivo/2018/07-12. Acesso em: 21 jan. 2020.

WIKIPÉDIA: Cinco pilares. Disponível em: https://pt.wikipedia.org/wiki/ Wikip\%C3\%A9dia:Cinco_pilares. Acesso em: 16 abr. 2019.

WIKIPÉDIA: Direito a voto. Disponível em: https://pt.wikipedia.org/wiki/ Wikip\%C3\%A9dia:Direito_a_voto. Acesso em: 21 jan. 2020.

WIKIPÉDIA: Escolha do artigo em destaque. Disponível em https://pt.wikipedia.org/ wiki/Wikip\%C3\%A9dia:Escolha_do_artigo_em_destaque e https://pt.wikipedia.org/ wiki/Wikip\%C3\%A9dia:O_que_\%C3\%A9_um_artigo_em_destaque\%3F. Acesso em: 21 jan. 2020.

WIKIPÉDIA: Escolha do artigo em destaque/Antiquário. Disponível em: https:// pt.wikipedia.org/wiki/Wikip\%C3\%A9dia:Escolha_do_artigo_em_destaque/ Antiqu\%C3\%A1rio. Acesso em: 20 jan. 2020.

WIKIPÉDIA: Escolha do artigo em destaque/História dos conceitos. Disponível em: https://pt.wikipedia.org/wiki/Wikip\%C3\%A9dia:Escolha_do_artigo_em_destaque/ Hist\%C3\%B3ria_dos_conceitos. Acesso em: 20 jan. 2020.

WIKIPÉDIA: Escolha do artigo em destaque/História pública. Disponível em: https:// pt.wikipedia.org/wiki/Wikip\%C3\%A9dia:Escolha_do_artigo_em_destaque/ Hist\%C3\%B3ria_p\%C3\%BAblica. Acesso em: 20 jan. 2020.

WIKIPÉDIA: Escolha do artigo em destaque/História do tempo presente. Disponível em https://pt.wikipedia.org/wiki/Wikip\%C3\%A9dia:Escolha_do_artigo_em_destaque/ Hist\%C3\%B3ria_do_tempo_presente. Acesso em: 20 jan. 2020. 
WIKIPÉDIA: Estatísticas. Disponível em https://pt.wikipedia.org/wiki/ Wikipédia:Estatísticas. Acesso em: 30 abr. 2019.

WIKIPÉDIA: O que é um artigo em destaque?. Disponível em: https://pt.wikipedia.org/ wiki/Wikip\%C3\%A9dia:O_que_\%C3\%A9_um_artigo_em_destaque\%3F. Acesso em: 27 jan. 2020.

WIKIPÉDIA: Outreach Dashboard/UFSC/Teoria da História na Wikipédia. Disponível em: https://pt.wikipedia.org/wiki/Wikip\%C3\%A9dia:Outreach_Dashboard/UFSC/ Teoria_da_Hist\%C3\%B3ria_na_Wikip\%C3\%A9dia. Acesso em: 27 jan. 2020.

WIKIPÉDIA: Páginas para eliminar/Marieta de Moraes Ferreira. Disponível em: https:// pt.wikipedia.org/wiki/Wikip\%C3\%A9dia:P\%C3\%A1ginas_para_eliminar/Marieta_de_Moraes_Ferreira. Acesso em: 21 jan. 2020.

WIKIPÉDIA: Páginas para eliminar/Pieter Lagrou. Disponível em: https://pt.wikipedia. org/wiki/Wikip\%C3\%A9dia:P\%C3\%A1ginas_para_eliminar/Pieter_Lagrou. Acesso em: 21 jan. 2020.

WIKIPÉDIA: Páginas para eliminar/Rodrigo Patto Sá Motta, [...]/Carlos Fico. Disponível em: https://pt.wikipedia.org/wiki/Wikip\%C3\%A9dia:P\%C3\%A1ginas_para_eliminar/Rodrigo_Patto_S\%C3\%A1_Motta, https://pt.wikipedia.org/wiki/ Wikip\%C3\%A9dia:P\%C3\%A1ginas_para_eliminar/Carlos_Fico. Acesso em: 21 jan. 2020.

WIKIPÉDIA: Páginas para eliminar/Verena Alberti. Disponível em: https://pt.wikipedia. org/wiki/Wikip\%C3\%A9dia:P\%C3\%A1ginas_para_eliminar/Verena_Alberti. Acesso em: 21 jan. 2020.

WIKIPÉDIA: Princípio da imparcialidade. Disponível em: https://pt.wikipedia.org/wiki/ Wikip\%C3\%A9dia:Princ\%C3\%ADpio_da_imparcialidade. Acesso em: 21 jan. 2020. WIKIPÉDIA: Verificabilidade. Disponível em: https://pt.wikipedia.org/wiki/Wikip\%C 3\%A9dia:Verificabilidade. Acesso em: 20 jan. 2020.

WIKIPÉDIA: Wikipédia em outras línguas. Disponível em: https://pt.wikipedia.org/wiki/ Wikip\%C3\%A9dia:Wikip\%C3\%A9dia_em_outras_1\%C3\%ADnguas. Acesso em: 30 abr. 2019.

WIKIPÉDIA: Wikipédia na Universidade. Disponível em: https://pt.wikipedia.org/wiki/ Wikip\%C3\%A9dia:Wikip\%C3\%A9dia_na_Universidade. Acesso em: 20 abr. 2019.

WIKIPÉDIA: Wikipédia na Universidade/Cursos. Disponível em: https://pt.wikipedia. org/wiki/Wikip\%C3\%A9dia:Wikip\%C3\%A9dia_na_Universidade/Cursos. Acesso em: 30 abr. 2019.

\section{NOTAS}

${ }^{1}$ No momento em que escrevemos este artigo, de acordo com as estatísticas de tráfego da internet fornecidas pelo Alexa, a Wikipédia é o quinto site mais acessado - ficando atrás 
dos motores de busca Google e Baidu, da rede social Facebook e da plataforma de compartilhamento de vídeos Youtube (Alexa). Ela está disponível para consulta em 260 idiomas. A versão lusófona possui 1.003.690 artigos válidos, contando com 2.241 .072 de usuários registrados, sendo 5.828 ativos (Wikipédia; Wikipédia: Estatísticas).

${ }^{2}$ Muitas das iniciativas associadas à Wikipédia na universidade indicam que a rejeição, por parte dos professores, à consulta da plataforma pelos discentes deve ser superada em virtude da efetiva participação desses alunos na melhoria do conteúdo da enciclopédia, aliada à promoção da educação tecnológica de seus participantes (Marques, 2013, p. 331-333). Nessa dupla chave, trabalhar a redação de verbetes na Wikipédia com viés didático contribui para "reafirmar as limitações de todas as fontes de informação [...] e enfatiza[r] as habilidades de análise crítica de fontes primárias e secundárias" (Rosenzweig, 2006, p. 137).

${ }^{3}$ Lançado pela Fundação Wikimedia, tem como objetivo incentivar a comunidade acadêmica a utilizar a Wikipédia enquanto "ferramenta de ensino, capacitando novos wikipedistas, desenvolvendo habilidades e competências, produção colaborativa de conhecimento livre, e principalmente contribuindo para a melhoria da qualidade da Wikipédia em Português" (Wikipédia na...).

${ }^{4}$ De acordo com a lista de projetos ligados à Wikipédia na Universidade (WIKIPÉDIA: Wikipédia na Universidade...).

${ }^{5}$ As informações sobre o projeto foram retiradas da página oficial na Wikipédia (Wikipédia: Outreach Dashboard).

${ }^{6}$ De acordo com as informações obtidas no histórico da página de cada verbete, Antiquário foi publicado em 27 de junho de 2018, História do tempo presente em 12 de julho de 2018, Scriptorium em 27 de julho de 2018, História global em 11 de agosto de 2018, Escola metódica em 23 de agosto de 2018, Historicismo em 18 de janeiro de 2019, História dos conceitos em 30 de janeiro de 2019, História pública em 14 de fevereiro de 2019, Romance histórico em 25 de julho de 2019 e Filosofia da história em 22 de agosto de 2019.

${ }^{7}$ Dados obtidos em Pageviews. Visualizações da página.

${ }^{8}$ Pela própria dinâmica da Wikipédia, é impossível verificar quem são os leitores desses verbetes; se estudantes de graduação, pós-graduação, professores ou público leigo interessado, tanto por causa do anonimato pregado pela plataforma quanto pela ausência de estudos satisfatórios sobre o perfil dos usuários da Wikipédia lusófona. No entanto, dois grandes estudos traçaram o perfil dos usuários e colaboradores da Wikipédia em todas as línguas: Glott; Schmidt; Ghosh, 2010 e Pande, 2011.

${ }^{9} \mathrm{O}$ princípio da neutralidade ou imparcialidade justifica-se também na tentativa de impedir conteúdo publicitário na enciclopédia. Sem esse mecanismo, empresas poderiam obter publicidade gratuita através da inserção de conteúdo parcial e com conflito de interesse, a exemplo do que aconteceu com a Pirelli em 2014 (Machuy, 2016, p. 11-17).

${ }^{10}$ Essas e as demais citações dessa EAD podem ser conferidas em Wikipédia: Escolha [...] História Pública.

${ }^{11}$ Universal Time Coordinated. 
${ }^{12}$ Conferir Wikipédia: [...] História do tempo presente.

${ }^{13}$ Não é novidade que demandas de cunho nacional se tornem objeto de disputa na Wikipédia lusófona, que agrega diversos países falantes do português. Essas polêmicas derivaram em reiterados pedidos de cisão da plataforma em português do Brasil e em português de Portugal entre 2005 e 2007 (Johnson, 2009).

${ }^{14}$ As discussões das eliminações estão preservadas em Wikipédia: [...] Verena Alberti; Wikipédia: [...] Pieter Lagrou; Wikipédia: [...] Rodrigo Patto Sá Motta [...] Carlos Fico; Wikipédia: [...] Marieta de Moraes Ferreira.

${ }^{15}$ História da Historiografia, principal e mais bem avaliado periódico brasileiro da área, mostra um pouco da pesquisa e escrita solitária do pesquisador. Na primeira década de existência da revista, em um total de 285 artigos publicados, apenas $8 \%$ foram escritos por grupos, sendo estes compostos por dois ou três autores (Varella, 2018, p. 242).

${ }^{16}$ Contudo, esse cenário não pode ser pintado como idílico, visto que existem muitas lutas e disputas dentro da Wiki-pt. Cf. Johnson (2009) e Machuy (2016).

Artigo recebido em 28 de janeiro de 2020.

Aprovado em 8 de julho de 2020. 